\title{
MUSGOS URBANOS DO RECANTO DAS EMAS, DISTRITO FEDERAL, BRASIL
}

\author{
Paulo Eduardo Câmara ${ }^{1}$ \\ Rodrigo Teixeira ${ }^{2}$ \\ Jaqueline Lima ${ }^{2}$ \\ Janaina Lima
}

Recebido em 24/10/2002. Aceito em 26/04/2003

\begin{abstract}
RESUMO - (Musgos urbanos do Recanto das Emas, Distrito Federal, Brasil). Fruto da ocupação desordenada de Brasília, o Recanto das Emas é uma das mais recentes cidades criadas no entorno da capital. Localizada a 25,8km do Plano Piloto, conta com área de 101.476km². O Recanto das Emas foi criado em 1993 e hoje conta com população de aproximadamente 100.000 habitantes. Foram selecionados vários pontos de coleta procurando abranger toda a cidade e diferentes áreas. Foram encontrados relativamente poucos representantes da brioflórula, com predomínio de espécies ruderais. A divisão Bryophyta conta com 10 espécies e sete famílias, destacando-se a família Bryaceae com três espécies. Barbula indica (Hook.) Spreng. é citada pela primeira vez para a região Centro-Oeste. Os resultados explicam-se pelo pouco tempo de existência da cidade, que conta com poucos substratos para fixação das populações de briófitas e não permitiram ainda o estabelecimento de nova cobertura vegetal.
\end{abstract}

Palavras-chaves - briófitas, brioflora urbana, musgos, Recanto das Emas, Distrito Federal

\begin{abstract}
Urban mosses from Recanto das Emas, Distrito Federal, Brazil). As a result of a disordered occupation of Distrito Federal, Recanto das Emas is one of the most recent cities that has been created around Brasilia, located at $25.8 \mathrm{~km}$ from the Plano Piloto and founded in 1993 , the city has an area of $101,476 \mathrm{~km}^{2}$ with a today's population around 100.000 habitants. Several points of collect were chosen trying to cover all city and different areas. Very few specimens of Brioflora were found. Bryophyta has 10 species, distributed within seven families. The most representative is the family Bryaceae, with three species. Barbula indica (Hook.) Spreng. is the first occurrence to the Centro-Oeste region. The results is explained by the few years of existence of the city and the lack of substrata which has not allowed the establishment of a new vegetable covering.
\end{abstract}

Key words - Bryophytes, urban brioflora, mosses, Recanto das Emas, Distrito Federal

1 Departamento de Botânica, Universidade de Brasília, UnB \& Missouri Botanical Garden, PoBOX 299, Saint Louis - MO 63110 (paulo.camara@mobot.org)

2 Faculdade da Terra de Brasília, FTB, Av. Recanto das Emas, Q203, Área Especial, Lote 32, CEP 70000-000, Brasília, DF, Brasil 


\section{Introdução}

As briófitas latu sensu constituem o segundo maior grupo de plantas terrestres seguindo-se às plantas vasculares (Buck 2000). Apesar disso, os estudos do grupo no Brasil ainda são escassos, especialmente se comparados com os grupos fanerogâmicos.

Neste contexto, a brioflora do Distrito Federal é particularmente pouco conhecida. Os trabalhos que citam briófitas para a região, o fazem dentro de contexto mais amplo de briófitas do cerrado, ou de revisões de gêneros e teses que incluem material do DF. Os primeiros estudos específicos para a região foram realizados pelo pesquisador científico Daniel Vital, do Instituto de Botânica de São Paulo, em expedição a Brasília em 1984, sem que os resultados fossem devidamente publicados. Após quase uma década deste evento, uma listagem prévia para a região do cerrado foi preparada por Filgueiras e Pereira (1993). Recentemente, foi feito o levantamento das briófitas das matas de galeria da Reserva Ecológica do IBGE, DF (Câmara 2002).

No que diz respeito às briófitas urbanas poucos são os trabalhos publicados no Brasil. O primeiro estudo abordando o tema foi o de Hell (1969), que realizou o levantamento das briófitas talosas de São Paulo. Posteriormente, Visnadi \& Monteiro (1990) publicaram sobre as briófitas urbanas da cidade de Rio Claro, SP; Bastos \& Yano (1993) estudaram os musgos urbanos da cidade de Salvador, B A, e Lisboa \& Ilkiu-Borges (1995) inventariaram a brioflora urbana de Belém, PA.

As briófitas são plantas com grande potencial bioindicador, estando diretamente relacionadas com a qualidade do ar, bem como com alterações decorrentes da urbanização.

Sendo o Recanto das Emas uma cidade nova, fundada em 1993, este trabalho irá proporcionar dados para o acompanhamento a médio e a longo prazos das variações na brioflora do local, bem como irá servir de subsídios para estudos posteriores em monitoramento ambiental e ecologia de briófitas.

A ausência de conhecimento sobre a brioflora do Distrito Federal, especialmente a urbana, e o fato da cidade estar em pleno processo de desenvolvimento, foram os fatores motivantes deste trabalho que pretende contribuir para o melhor conhecimento da brioflora urbana e da flora da região Centro-Oeste.

\section{Material e métodos}

Área estudada - Fruto da ocupação desordenada de Brasília, o Recanto das Emas é uma das mais recentes cidades satélites criadas no entorno da capital, localizada a $25,8 \mathrm{~km}$ do centro do Plano Piloto. A região tem clima com duas estações bem definidas, uma fria e seca (entre maio e setembro) e outra quente e úmida (entre outubro e abril). Segundo a classificação de Köppen, o clima é Aw, ou seja, tropical de savana (Sematec 1992).

Contando com área de $101,476 \mathrm{~km}^{2}$, o Recanto das Emas foi criado em 28/julho/1993 por Lei Distrital, abrigando população de aproximadamente 100.000 habitantes, que vive, em sua maioria, em condições ainda precárias de habitação e saneamento. Toda a estrutura da cidade é muito recente; as ruas, com exceção de apenas uma, não possuem pavimentação asfáltica, nem ornamentação vegetal.

A forma rápida com surgiu a cidade devastou a flora sem que nenhum levantamento florístico fosse feito na região, não existindo dados sobre a brioflora nativa.

A paisagem do Recanto das Emas está em constante transformação, com o surgimento diário de novas edificações e obras. Não existe sistema eficaz de escoamento das águas pluviais; durante as chuvas, as enxurradas levam muros e arrastam sedimentos por grandes distâncias. $\mathrm{Na}$ cidade, não existem praças ou jardins, apenas casas e comércio. A população convive com solo exposto, poeira e muita lama.

A vegetação existente hoje no local é pequena, sendo composta, em sua maioria, por 
indivíduos geralmente jovens, pertencentes a gêneros exóticos como Ficus, Mangifera, Eucalyptus e Pinus.

Amostragem - As coletas foram feitas em todo o perímetro urbano, entre janeiro e julho/2001. A preservação do material seguiu as recomendações de Yano (1984).

Para a análise de material utilizou-se microscópio óptico e estereomicroscópio. Quando necessário, lâminas semipermanentes foram feitas com solução de Hoyer (Schuster 1966). Para as identificações utilizaram-se chaves e literatura especializada (Griffin III 1979; Lisboa 1993; Zander 1993; Sharp et al. 1994; Buck 1998; e Oliveira-e-Silva \& Yano 2000).

$\mathrm{O}$ material coletado foi incorporado ao Herbário da Universidade de Brasília (UB) e o sistema de classificação utilizado foi o de Vitt (1984) para Bryophyta.

Os táxons são apresentados por ordem alfabética de família e gênero.

A distribuição geográfica foi baseada em: Yano (1981), Frahm (1991), Reese (1993), Pôrto et al. (1994), Vital \& Visnadi, (1994), Yano (1994), Lisboa \& Ilkiu-Borges (1995), Yano (1995), Visnadi \& Vital, (1997), Vilas BôasBastos \& Bastos (1998), Oliveira-e-Silva \& Yano (2000), Yano \& Colletes (2000), Câmara (2002) e Castro et al. (2002).

\section{Resultados e discussão}

Foram encontradas 13 espécies de briófitas, pertencentes a 10 famílias. As famílias mais representativas foram Bryaceae (três espécies) e Pottiaceae (duas espécies). Barbula indica (Hook.) Spreng. é a primeira citação de ocorrência para a região Centro-Oeste, apesar de ser espécie comum em centros urbanos. Este fato demonstra o baixo conhecimento do grupo na região. Infelizmente, boa parte do material era encontrado em pouca quantidade e de forma esparsa, o que dificultou ou até impossibilitou a identificação a nível de espécie de algumas coletas.

\section{Família Bryaceae}

Bryum argenteum Hedw., Spec. Musc. 181. 1801

Ilustração e descrição: Sharp et al. (1994). Material analisado: BRASIL. Distrito Federal: Recanto das Emas, sobre solo, área residencial, 16/IIII/2001, Lima \& Teixeira $s / n$ (UB); ibidem, Campus I da Faculdade da Terra, próximo bloco F, 16/III/2001, Lima \& Teixeira $s / n$ (UB); ibidem, administração do Recanto das Emas, 16/III/2001, Câmara et al. s/n (UB).

Distribuição geográfica: Região Norte: AM. Região Nordeste: AL, BA, PB, PE. Região Sudeste: ES, MG, RJ, SP. Região Sul: PR, RS, SC. Região Centro-Oeste: DF, GO, MT.

Comentários: freqüente no solo, ocorre no campus da Faculdade da Terra de Brasília (FTB), bem como no solo da Administração Regional do Recanto das Emas. Foi encontrado material fértil em abundância no campus da FTB.

Bryum capillare Hedw., Spec. Musc. 182. 1801.

Ilustração e descrição: Lisboa (1993).

Material analisado: BRASIL. Distrito

Federal: Recanto das Emas área residencial, 16/III/2001, Lima \& Teixeira s/n (UB).

Distribuição geográfica: Região Norte: PA, RO. Região Nordeste: PI. Região Sudeste: ES, SP. Centro-Oeste: DF.

Comentários: coletado somente em solo argiloso. Não foi encontrado fértil. Geralmente associado com Bryum coronatum Schwaegr.

Bryum coronatum Schwaegr., Sup. Spec. Musc. 1(2): 103. 1816.

Ilustração e descrição: Lisboa (1993).

Material analisado: BRASIL. Distrito Federal: Recanto das Emas, Campus da FTB, bloco A, 16/III/2001, Lima \& Teixeira s/n (UB); ibidem, Campus da FTB, bloco B, 16/III/2001, Lima \& Teixeira $s / n$ (UB).

Distribuição geográfica: Região Norte: AM, AC, PA, RO, RR. Região Nordeste: BA, FN, PB, 
PE. Região Sudeste: MG, RJ, SP. Região Sul: PR, RS, SC. Região Centro-Oeste: GO, MT, DF.

Comentários: coletado sempre no solo, muitos representantes férteis, ocorre geralmente associado com Bryum capillare Hedw. Encontrado na Administração Regional do Recanto das Emas e em frente a residências.

\section{Família Calymperaceae}

Syrropodon ligulatus Mont., Syll. Gen. Sp. Crypt 47. 1856.

Ilustração e descrição: Sharp et al. (1994).

Material analisado: BRASIL. Distrito Federal: Recanto das Emas, epifitando árvore, 16/III/2001, Lima \& Teixeira s/n (UB).

Distribuição geográfica: Região Norte: AM, AP, PA, RO, RR. Região Nordeste: BA, PE. Região Sudeste: MG, SP. Região CentroOeste: GO, MT e DF.

Comentários: epífita sempre estéril, pouco frequiente. Por vezes ocorre próximo a Fabronia ciliaris var. polycarpa.

\section{Família Dicranaceae}

\section{Campylopus sp.}

Material analisado: BRASIL. Distrito Federal: Recanto das Emas, Administração Regional do Recanto das Emas, sobre casca de árvore, 16/III/2001, Lima s/n (UB).

Comentários: epífita na Administração Regional do Recanto das Emas, com apenas uma coleta fragmentada; a identificação a nível de espécie não foi possível. Rara.

\section{Família Entodontaceae}

Erythrodontium squarrosum (C.M.) Par. Index Bryol. Ed. 2, 2:159. 1904.

Ilustração e descrição: Buck (1998).

Material analisado: BRASIL. Distrito

Federal: Recanto das Emas, Administração Regional do Recanto das Emas, epífita em Eucalipto, 16/III/2001, Lima \& Teixeira s/n(UB). Distribuição geográfica: Região Sudeste:
ES, MG, RJ, SP. Região Sul: PR, RS, SC. Região Centro-Oeste: GO, MT e DF.

Comentários: epífita em eucaliptos na Administração Regional do Recanto das Emas, muito rara.

\section{Família Fabroniaceae}

Fabronia ciliaris (Brid.) Britt, Bryol. Univ. 2:171 1827. var. polycarpa (Hook.) Buck. Brittonia 35(3): 251. 1983.

Ilustração e descrição: Sharp et al. (1994). Material analisado: BRASIL. Distrito Federal: Recanto das Emas, epifitando árvore, 16/III/2001, Lima \& Teixeira s/n (UB); ibidem, 27/IV/2001, Câmara et al. s/n (UB).

Distribuição geográfica: Região Nordeste: BA, CE, PE, SE. Região Sudeste: ES, RJ, SP. Região Sul: PR, RS, SC. Região Centro-Oeste: DF. Comentários: epífita em troncos de árvores na Administração Regional do Recanto das Emas, comum neste local. Não foi encontrada fora da administração.

\section{Família Fissidentaceae}

Fissidens sp.

Material analisado: BRASIL. Distrito Federal: Recanto das Emas, Administração Regional do Recanto das Emas, 27/IV/2001, Lima \& Teixeira $s / n$ (UB).

Comentários: com apenas uma ocorrência, estéril, na base de árvores na Administração Regional do Recanto das Emas. A quantidade de material revelou-se insuficiente para uma identificação confiável a nível de espécie.

\section{Família Funariaceae}

Funaria hygrometrica Hedw. Spec. Musc. 172. 1801.

Ilustração e descrição: Lisboa (1993).

Material analisado: BRASIL. Distrito Federal: Recanto das Emas, Administração Regional do Recanto, solo, próximo a córrego, 27/IV/2001, Lima s/n (UB). 
Distribuição geográfica: Região Norte: AM. Região Sudeste: MG, RJ, SP. Região Sul: PR e SC. Região Centro-Oeste: GO, MT e DF.

Comentários: ocorre nos solos, córrego Vargem da Bênção, rara.

\section{Família Leucobryaceae}

Octoblepharum albidum Hedw., Spec. Musc. 50. 1801.

Ilustração e descrição: Sharp et al. (1994). Material analisado: BRASIL. Distrito Federal: Recanto das Emas, epifitando árvore, 16/III/2001, Lima \& Teixeira s/n (UB).

Distribuição geográfica: Região Norte: AC, AM, AP, PA, RO, RR. Região Nordeste: BA, CE, FN, MA, PB, PE, PI, SE. Região Sudeste: ES, MG, RJ, SP. Região Sul: PR e SC. Região Centro-Oeste: DF, GO, MT.

Comentários: epífita na Administração Regional do Recanto das Emas, freqüente neste local, não foi encontrado em outros ambientes.

\section{Família Pottiaceae}

Barbula indica (Hook.) Spreng., Nomencl. Bot. 2:72. 1824.

Ilustração e descrição: Saito (1975).

Material analisado: BRASIL. Distrito

Federal: Recanto das Emas, Administração Regional do Recanto, 16/III/2001, Lima \& Teixeira s/n (UB); Ibidem, 16/III/2001, Câmara et al. (UB).

Distribuição geográfica: Região Nordeste: BA. Região Sudeste: ES, MG e SP. Região Centro-Oeste: Primeira citação de ocorrência.

Comentários: ocorre sempre associada com Hyophylla involuta (Hook) Jaeg., sempre estéril, rara.

Hyophylla involuta (Hook) Jaeg., Ber. Thätigk. St. Gallischen. Naturwiss. Gesel.1871-1872:354 1873.

Ilustração e descrição: Sharp et al. (1994) Material analisado: BRASIL. Distrito Federal: Recanto das Emas, área residencial,
16/III/2001, Lima \& Teixeira s/n (UB); ibidem, Administração Regional do Recanto das Emas, 16/III/2001, Lima \& Teixeira $s / n$ (UB).

Distribuição geográfica: Região Norte: AM, PA, RO. Região Nordeste: BA, PB, PI, RN. Região Sudeste: ES, RJ, SP. Região Sul: PR, RS. Região Centro Oeste: GO e DF.

Comentários: sempre estéril, presente no solo. Nas áreas residenciais, comerciais e administrativa, frequiente.

\section{Família Sematophyllaceae}

Sematophyllum subpinnatum (Brid.) Britt. Briologist 21:28. 1918.

Ilustração e descrição: Buck (1998).

Material analisado: BRASIL. Distrito

Federal: Recanto das Emas, epifitando árvore, 16/III/2001, Lima \& Teixeira s/n (UB); ibidem, 16/III/2001, Lima s/n(UB); ibidem, 27/IV/2001, Câmara et al. s/n (UB).

Distribuição geográfica: Região Norte: AC, AM, AP, RO, RR. Região Nordeste: BA, CE, PA, PB, PE. Região Sudeste: ES, MG, RJ, SP. Região Sul: PR, RS, SC. Região Centro-Oeste: DF.

Comentários: epífita na Administração Regional do Recanto das Emas, rara.

A Administração Regional do Recanto das Emas foi o local onde se encontrou a maior riqueza de briófitas. As árvores que lá se encontram são eucaliptos e pinheiros de grande porte, que provavelmente já existiam ali antes da construção da cidade. Estas árvores criam ambiente mais propício ao desenvolvimento de briófitas, pois fornecem mais sombra e umidade.

Espera-se que este trabalho sirva de subsídio para posteriores estudos sobre brioflora no local, bem como sirva como um bom modelo para acompanhamento de processos de colonização de áreas urbanas. O fato de haver pequena quantidade e baixa riqueza de briófitas, por si só, constitui importante informação para estudos futuros. 
Os resultados explicam-se pelo pouco tempo de existência da cidade, que conta com poucos substratos para fixação das populações, em virtude de edificações bastante recentes e em constantes transformações. Observam-se, também, poucas árvores, em sua maioria bem jovens e recém introduzidas. Além disso, devido ao precário sistema de escoamento de águas pluviais, durante as chuvas ocorrem grandes enxurradas de lama que arrastam o solo e criam grandes erosões que se transformam constantemente. Esses fatores não permitiram, ainda, o estabelecimento de uma nova cobertura vegetal.

\section{Agradecimentos}

Os autores agradecem ao Pesquisador Científico Daniel Moreira Vital, do Instituto de Botânica de São Paulo, pela concessão de parte importante da literatura; aos Doutores Pedro Américo Cabral Senna (in memoriam); à Sandra Visnadi, pela revisão do texto e pelas sugestões apresentadas. Agradecem também à Coordenação do curso de Biologia, ao Centro de Pesquisa e Extensão (CEPE) e à Direção da Faculdade da Terra de Brasília, FTB, pelo incentivo e financiamento deste estudo.

\section{Referências bibliográficas}

Bastos, C. J. P. \& Yano, O. 1993. Musgos da zona urbana de salvador, Bahia, Brasil. Hoehnea 20(1/2): 23-33.

Buck, W. R. 1998. Pleurocarpous Mosses of West Indies. Memoirs of New York Botanical Garden, New York, v. 82.

Buck, W. R. 2000. Morphology and Classification of Mosses. in A. Shaw \& B. Goffinet. Bryophyte Biology. Cambridge University Press, Cambridge.

Câmara, P. S. 2002. Levantamento da brioflora das Matas de Galeria da Reserva ecológica do IBGE, DF. Dissertação de Mestrado. Universidade de Brasília, UnB, DF.

Castro, M. N. C. F.; Porto, K. C.; Yano, O. \& Castro, A. A. J. F. 2002. Levantamento florístico de Bryopsida de Cerrado e Mata Ripícola do Parque Nacional de Sete Cidades, Piauí, Brasil. Acta Botanica Brasilica 16(1): 61-76.
Filgueiras, T. S. \& Pereira, B. A. S. 1993. Briófitas in Flora do Distrito Federal. Pp. 364-366. In: (M. N. Pinto, org.). Cerrado: Caracterização Ocupação e Perspectivas.

Frahm, J. P. 1991. Dicranaceae: Campylopodioideae, Paraleucobryoideae. Flora Neotropica. Monograph 54: 1-238.

Griffin III, D. 1979. Guia Preliminar Para as briófitas freqüentes em Manaus e adjacências. Acta Amazonica 9(3): 1-67.

Hell, K. G. 1969. Briófitas talosas dos arredores da cidade de São Paulo (Brasil). Boletim de Botânica da Faculdade de Filosofia, Ciências e Letras da Universidade de São Paulo 335(25): 1-187.

Lisboa, R. C. L. 1993. Musgos Acrocárpicos do estado de Rondônia. Coleção Adolpho Ducke.

Lisboa, R. C. L. \& Ilkiu-Borges, A. L. 1995. Diversidade das briófitas de Belém (PA) e seu potencial como indicadoras de poluição. Boletim do Museu Paraense Emílio Goeldi, série Botânica 11(2): 131-293.

Oliveira-e-Silva, M. I. \& Yano, O. 2000. Musgos de Mangaratiba e Angra dos Reis. Rio de Janeiro, Brasil. Boletim do Instituto de Botânica 14: 1-137.

Porto, K. C.; Silveira M. F. G.; \& Sá, P. S. A. 1994. Briófitas da Caatinga 1. Estação experimental do IPA, Caruaru, PE. Acta Botanica Brasilica 8(1): 77-85.

Reese, W. D. 1993. Calymperaceae. Flora Neotropica. Monograph 58: 1-102.

Saito, K. 1975. A monograph of Japanese Pottiaceae (Musci). The Journal of the Hattori Botanical Laboratory 39: 373-537.

Schuster, R. M. 1966. The Hepaticae and Anthocerotae of North America. East of Hundredth Meridian. Columbia Press, New York.

Sematec (1992). Mapa Ambiental do Distrito Federal. Secretaria do Meio Ambiente Ciência e Tecnologia do Governo do Distrito Federal, Brasília.

Sharp, A. J.; Crum, H. A. \& Eckel, P. 1994. The moss flora of Mexico. Memoirs of the New York Botanical Garden, New York, v. 69.

Vilas Bôas-Bastos, S. B. \& Bastos, C. J. P. 1998. Briófitas de uma área de cerrado no município de Alagoinhas, Bahia, Brasil. Tropical Bryology 15: 101-110.

Visnadi, S. R. \& Monteiro, R. 1990. Briófitas da cidade de Rio Claro, Estado de São Paulo, Brasil. Hoehnea 17(1): 71-84.

Visnadi, S. R \& Vital, D. M. 1997. Bryophytes from greenhouses of the Institute of Botany, São Paulo, Brazil. Lindbergia 22: 44-46.

Vital, D. M. \& Visnadi, S. R. 1994. Bryophytes of Rio Branco municipality, Acre, Brazil. Tropical Bryology 9: 69-74. 
Vitt, D. H. 1984. Classification of the Bryopsida. In R. M. Schuster (ed.). New Manual of Bryology 2: 696-759.

Yano, O. 1981. A Checklist of Brazilian mosses. The Journal of the Hattori Botanical Laboratory 50: 279-456.

Yano, O. 1984. Briófitas. Pp. 27-30. In: O. Fidalgo \& V. Bononi (coord.). Técnicas de coleta, Preservação e Herborização de Material botânico. Série Documentos, Instituto de Botânica de São Paulo.
Yano, O. 1994. Briófitas da Serra da Itabaiana, Sergipe, Brasil. Acta Botanica Brasilica 8: 45-57.

Yano, O. 1995. A new additional annotated checklist of Brazilian bryophytes. The Journal of the Hattori Botanical Laboratory 78: 137-182.

Yano, O. \& Colletes, A. G. 2000. Briófitas do Parque Nacional de Sete Quedas, Guaira, PR, Brasil. Acta Botanica Brasilica 14(2): 212-242.

Zander, R. 1993. Genera of the Pottiaceae: Mosses of Harsh Environments. Bulletin of the Buffalo Society of Natural Sciences, v. 32. 